\title{
Extractive and Catalytic Oxidative Desulfurization of Gasoline by Methyltrioxorhenium in Ionic Liquids
}

\author{
Mingdong Zhou, ${ }^{\dagger}$ Wenye Meng, ${ }^{\dagger}$ Yang Li, $^{\dagger}$ Qiang Wang, ${ }^{\dagger}$ Xuebing Li, ${ }^{*},{ }^{\ddagger}$ and Shuliang Zang ${ }^{*}{ }^{\dagger}$ \\ ${ }^{\dagger}$ School of Chemical and Material Science, Liaoning Shihua University, Dandong Road, Fushun 113001, People’s Republic of China \\ ${ }^{\ddagger}$ Key Laboratory of Biofuels, Qingdao Institute of Bioenergy and Bioprocess Technology, Chinese Academy of Sciences, Qingdao \\ 266101, People's Republic of China
}

\begin{abstract}
For the first time, methyltrioxorhenium (MTO) is used as a catalyst for the extractive and catalytic oxidative desulfurization (ECODS) of model oil and fluid catalytic cracking (FCC) gasoline, with $30 \% \mathrm{H}_{2} \mathrm{O}_{2}$ as the oxidant and ionic liquids as the solvent and extractant for the removal of organic sulfur at moderate temperatures (below $60{ }^{\circ} \mathrm{C}$ ). The ECODS is highly efficient with low catalyst loading ( $1-5 \mathrm{~mol} \%)$. The mono- and bisperoxorhenium compounds formed via the reactions of MTO and $\mathrm{H}_{2} \mathrm{O}_{2}$ are proven to be catalytic active species for the oxidation of organic sulfides, such as thioethers, thiophene, and alkyl thiophenes contained in the FCC gasoline. After the oxidation, the oxidized products were easily extracted into the ionic liquid phase from the oil phase. The sulfur removal can reach up to $99 \%$ for the model oil (with an initial sulfur content of $200 \mu \mathrm{g} / \mathrm{mL}$ ) and $91 \%$ of the Fushun FCC gasoline (with an initial sulfur content of ca. $142 \mu \mathrm{g} / \mathrm{mL}$ ) within $2 \mathrm{~h}$ under the optimized conditions. The octane number of the gasoline is reduced by only about 0.7 , without significant changes in hydrocarbon group composition after desulfurization.
\end{abstract}

\section{INTRODUCTION}

The emission of $\mathrm{SO}_{x}$ originated from the combustion of liquid fuels is a major cause of air pollution. To protect the environment against $\mathrm{SO}_{x}$ pollution, many stringent environment legislations have been issued to limit the sulfur content of fuels. For gasoline, the new standard of sulfur content may be restrained to less than $10 \mu \mathrm{g} / \mathrm{mL}$ in most countries in the future. $^{1-3}$ Thus, the deep desulfurization of gasoline has become an important research topic.

Currently, hydrodesulfurization (HDS) has been widely employed to remove the organic sulfur-containing compounds from fuels in industrial refineries. To produce cleaner gasoline (with the sulfur content lower than $10 \mu \mathrm{g} / \mathrm{mL}$ ), higher pressure and/or temperature have to be applied in the HDS process. However, the octane number (RON or MON) for gasoline would decrease significantly because of the excessive hydrogenation process. ${ }^{4}$ Also, the production cost would increase, owing to the higher energy consumption and the instrument renovation. ${ }^{4-7}$ It is thereby essential to develop a new effective and practical desulfurization process. Oxidative desulfurization (ODS) would be a promising alternative because it can remove most of the sulfur compounds in the gasoline under mild conditions (low temperature and pressure). ${ }^{8,9}$

In ODS, the efficient solvent is indispensable for the extraction of the oxidized sulfur compounds in the oil. Room-temperature ionic liquids (RTILs) are effective and environmentally benign solvents and extractants for the ODS process because of their excellent solubility toward many inorganic/organic compounds, high thermal stability, low volatility, and recyclability. Despite a lot of research work being performed using ionic liquids (ILs) as an extracting agent for the extractive desulfurization, the sulfur removal efficiency was not very high and a large amount of IL was generally necessary to increase the sulfur removal. ${ }^{10,11}$ The combination of the extraction and catalytic oxidation desulfurization (ECODS) process using ILs as solvents has been proven to be more efficient compared to the mere IL extraction. ${ }^{12,13}$ In ECODS, many oxidation catalysts, such as tungsten- or molybdenum-containing polyoxometalates (POMs), ${ }^{14}$ supported $\mathrm{V}_{2} \mathrm{O}_{5}{ }^{15}$ (on silica, ${ }^{16}$ alumina, ${ }^{16}$ or $\mathrm{TiO}_{2}{ }^{17}$ ), Ag/TS- $1,{ }^{18}$ Brønsted or Lewis acidic ILs, ${ }^{19}$ have been used in the presence of $\mathrm{H}_{2} \mathrm{O}_{2}$ as an oxidant for desulfurization in the literature. However, to the best of our knowledge, the organometallic catalyst, methyltrioxorhenium (MTO), has never been employed as a catalyst in the ECODS process. MTO, mainly studied by the research groups of Herrmann, ${ }^{20}$ Espenson, ${ }^{21}$ and Adam, ${ }^{22}$ is an extremely versatile catalyst or catalyst precursor for a broad variety of organic reactions, such as olefin oxidation, aromatic or sulfur compound oxidations, olefin metathesis, aldehyde olefination, etc. Among the plethora of applications, the oxidation reaction is one of the extensively examined. MTO can react with hydrogen peroxide to form mono- or bisperoxorhenium as the active species in catalytic oxidations, with only water as the byproduct, making such a reaction environmentally benign (Scheme 1$){ }^{23}$

Scheme 1. Reaction between MTO and $\mathrm{H}_{2} \mathrm{O}_{2}$

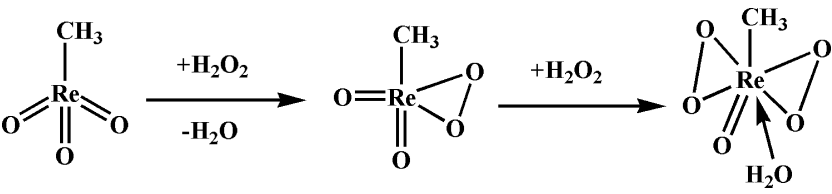

Received: October 23, 2013

Revised: December 1, 2013

Published: December 4, 2013 
It has also been proven that MTO is stable in the ionic liquid medium, ${ }^{24,25}$ and it is active toward the oxidation of sulfides $^{26,27}$ (Scheme 2). Therefore, it is interesting to investigate its catalytic potential for the oxidative desulfurization of gasoline.

Scheme 2. MTO Catalyzed the Oxidation of Sulfur Compounds

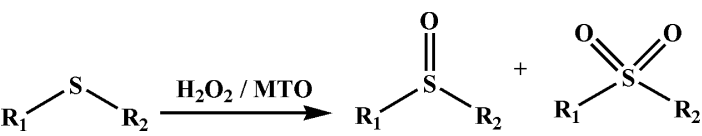

In this paper, we employed IL as a solvent and MTO as a catalyst for the ECODS of both model oil and Fushun fluid catalytic cracking (FCC) gasoline using $\mathrm{H}_{2} \mathrm{O}_{2}$ as the oxidant. The ECODS process was optimized on the basis of model oil and was then further applied to the Fushun FCC gasoline under the optimized conditions. The composition of organic sulfur compounds and hydrocarbons of Fushun FCC gasoline was also determined before and after the desulfurization process in our studies.

\section{EXPERIMENTAL SECTION}

2.1. Preparation of ILs and MTO. The ILs, 1-butyl-3methylimidazolium tetrafluoroborate $\left([\mathrm{BMIM}] \mathrm{BF}_{4}\right)$, 1-octyl-3-methylimidazolium tetrafluoroborate $\left([\mathrm{OMIM}] \mathrm{BF}_{4}\right), 1$-butyl-3-methylimidazolium hexafluorophosphate, $\left([\mathrm{BMIM}] \mathrm{PF}_{6}\right)$, and 1-octyl-3-methylimidazolium hexafluorophosphate $\left([\mathrm{OMIM}] \mathrm{PF}_{6}\right)$, were synthesized according to the published procedures. ${ }^{28}$ The ILs were fully purified through recrystallization from acetonitrile/ethyl acetate (1:2) twice to remove the impurities $\mathrm{NaBr}$ or $\mathrm{NaBF}_{4}$ dissolved in ILs. MTO was prepared through the $\mathrm{Zn}$ route as published in the literature. ${ }^{29}$ Yield = $90 \%$, as colorless needles, with melting point $(\mathrm{mp})=106^{\circ} \mathrm{C}$. Infrared (IR) $\left(\mathrm{cm}^{-1}, \mathrm{KBr}\right) \nu: 955\left(\mathrm{ReO}_{3}, \mathrm{vs}\right), 1000\left(\mathrm{ReO}_{3}, \mathrm{~s}\right)$. Proton nuclear magnetic resonance $\left({ }^{1} \mathrm{H} \mathrm{NMR}\right)\left(\mathrm{ppm}, 300 \mathrm{~Hz}, 25^{\circ} \mathrm{C}, \mathrm{CDCl}_{3}\right) \delta: 2.61$ $\left(\mathrm{s}, \mathrm{CH}_{3}\right)$.

2.2. Desulfurization Procedure. The desulfurization experiments were conducted in a $50 \mathrm{~mL}$ two-neck flask equipped with a condenser. In a typical run, $10 \mathrm{~mL}$ of model oil $(0.5 \mathrm{~g}$ of thiophene dissolved in $952 \mathrm{~mL}$ of $n$-octane, with a sulfur concentration of $200 \mu \mathrm{g} / \mathrm{mL}$ ) or the Fushun FCC gasoline (with the original sulfur concentration of 142 $\mu \mathrm{g} / \mathrm{mL}$ ) and a certain amount of ILs were added to the flask. The mixture was heated from room temperature to $60{ }^{\circ} \mathrm{C}$ in a water bath with stirring and kept at $60{ }^{\circ} \mathrm{C}$ for 1 to $3 \mathrm{~h}$.

2.3. Analysis. The sulfur compounds in the oil were separated with a SE-30 capillary column $(30 \mathrm{~m} \times 0.22 \mathrm{~mm} \times 0.25 \mu \mathrm{m})$ and analyzed with an Agilent gas chromatograph 7890A equipped with a flame photometric detector. The total sulfur content of both model oil and real gasoline was detected using a TS-2000 UV fluorescence sulfur analyzer (Jiangfen Electroanalytical Instrument, China). The detection limit and relative standard deviation (RSD) were $0.2 \mu \mathrm{g} / \mathrm{mL}$ and $\pm 2 \%$, respectively. The qualitative and quantitative hydrocarbon composition of the Fushun FCC gasoline were analyzed by a Varian 3800 gas chromatograph, according to the ASTM D6730 standard test method (standard test method for the determination of individual components in the spark ignition engine).

\section{RESULTS AND DISCUSSION}

In this work, both model oil and Fushun FCC gasoline were applied to the ECODS system. The system was composed of model oil (or Fushun FCC gasoline), $\mathrm{H}_{2} \mathrm{O}_{2}$ (30\%), ILs, and MTO. It is well-known that the major sulfur compounds in gasoline are mercaptan, thioether, thiophene, and their derivatives. Because thiophene and its derivatives are relatively more difficult to be removed from oil compared to others, we chose thiophene as the typical sulfur compound in the model oil, which composed of thiophene and n-octane with a sulfur concentration of $200 \mu \mathrm{g} / \mathrm{mL}$ was used as the model oil. The optimized reaction condition was determined with the model oil and then used for testing the desulfurization of real FCC gasoline.

3.1. Oxidative Desulfurization of Model Oil. The desulfurization experiments were initially carried out in four

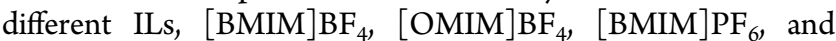
$[\mathrm{OMIM}] \mathrm{PF}_{6}$. All four ILs were immiscible with the model oil. MTO combined with $\mathrm{H}_{2} \mathrm{O}_{2}$ could be dissolved in watermiscible $[\mathrm{BMIM}] \mathrm{BF}_{4}$, which then formed a biphasic system with the model oil. However, in the case of water-immiscible ILs, $[\mathrm{OMIM}] \mathrm{BF}_{4},[\mathrm{BMIM}] \mathrm{PF}_{6}$, and $[\mathrm{OMIM}] \mathrm{PF}_{6}, \mathrm{H}_{2} \mathrm{O}_{2}$ existed as a single phase, thus forming triphasic systems. The blank experiment using IL $[\mathrm{BMIM}] \mathrm{BF}_{4}$ only for the extractive desulfurization showed a total sulfur removal of $35 \%$ (under the conditions of $1: 5 V_{\mathrm{IL}} / V_{\text {oil }}$ and $60{ }^{\circ} \mathrm{C}$ ). After adding an excess amount of $\mathrm{H}_{2} \mathrm{O}_{2}(30 \%)$ to the solution, the sulfur removal was increased up to ca. $55 \%$, implying that $\mathrm{H}_{2} \mathrm{O}_{2}$ can oxidize thiophene in the oil. Furthermore, the sulfur removal was increased markedly after adding MTO as the oxidation catalyst to the system. Under the conditions of model oil $=10$ $\mathrm{mL}, \mathrm{IL}=2 \mathrm{~mL}, n_{\mathrm{MTO}} / n_{\text {sulfur }}=3: 100, n_{\mathrm{H}_{2} \mathrm{O}_{2}} / n_{\text {sulfur }}=6, t=3 \mathrm{~h}$, and $T=60{ }^{\circ} \mathrm{C}$, the sulfur removal reached $99 \%$ for $[\mathrm{BMIM}] \mathrm{BF}_{4}, 91 \%$ for $[\mathrm{OMIM}] \mathrm{BF}_{4}, 98 \%$ for $[\mathrm{BMIM}] \mathrm{PF}_{6}$, and $93 \%$ for [OMIM] $\mathrm{PF}_{6}$. Because of the increased polarity of the obtained sulfoxide and sulfones after the oxidations (in comparison to thiophene), they were easily to be extracted to the strong polar IL phase; thus, the sulfur removal was highly increased. Although only a small amount of sulfur compounds is contained in the FCC gaslone, for a large-scale desulfurization process in industry, it would be important to isolate and collect the oxidized sulfur compounds and use them as byproducts from the ECODS process. Therefore, the oxidized products were further isolated and charaterized by ${ }^{1} \mathrm{H}$ NMR spectra in our studies. However, expected thiophene 1-oxide and thiophene 1,1-dioxide products were not detected according to the ${ }^{1} \mathrm{H}$ NMR spectra. Instead, a major product 3, as shown in Scheme 3, derived from self-cycloaddition of thiophene 1,1-dioxide and a very small amount of trimerization

Scheme 3. Cycloaddition Reaction of Thiophene 1,1-Dioxide

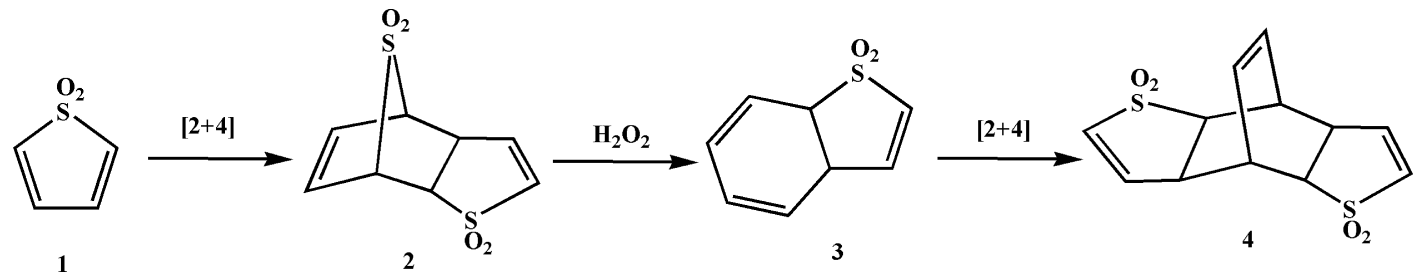


product 4 could be detected. ${ }^{30}$ Because thiophene 1,1-dioxide is a good dienophile, it is not a surprise that the oxidized compound further underwent a Diels-Alder self-cycloaddition reaction and formed the corresponding cycloaddition products 3 and 4 . $^{28,30}$ Product 3 showed chemical shifts (in $\mathrm{CDCl}_{3}$ ) at 4.06-4.15 (m, 2H), $5.66(\mathrm{~d} / \mathrm{d}, 1 \mathrm{H}), 5.88(\mathrm{~d} / \mathrm{d}, 1 \mathrm{H}), 6.04,(\mathrm{~m}$, $1 \mathrm{H}), 6.24,(\mathrm{dd}, 1 \mathrm{H}), 6.76$, (dd, $1 \mathrm{H})$, and 6.95, (dd, $1 \mathrm{H})$. The data were in accordance with the chemical shifts for 3 that had been reported by Nakayama et al. in the literature. ${ }^{30,31}$ However, the cycloaddition product derived from thiophene 1-oxide could not be seen in the ${ }^{1} \mathrm{H}$ NMR spectra. Because the oxidation was carried out under the presence of an excess amount of $\mathrm{H}_{2} \mathrm{O}_{2}$, we assume that the thiophene 1-oxide might be further oxidized to thiophene 1,1-dioxide; thus, only products 3 and 4 derived from thiophene 1,1-dioxide can be detected.

All of the ILs resulted in a high sulfur removal. However, because $[\mathrm{BMIM}] \mathrm{BF}_{4}$ forms a biphasic catalytic system, it is comparatively easier to study the extraction behavior compared to the triphasic system for $[\mathrm{OMIM}] \mathrm{BF}_{4},[\mathrm{BMIM}] \mathrm{PF}_{6}$, and $[\mathrm{OMIM}] \mathrm{PF}_{6}$. Therefore, $[\mathrm{BMIM}] \mathrm{BF}_{4}$ was used as a solvent for desulfurization in the further studies.

3.1.1. Influence of the Catalyst Loading on the Sulfur Removal. The effect of catalyst loading on the sulfur removal is shown in Figure 1. It can be seen that the sulfur removal was

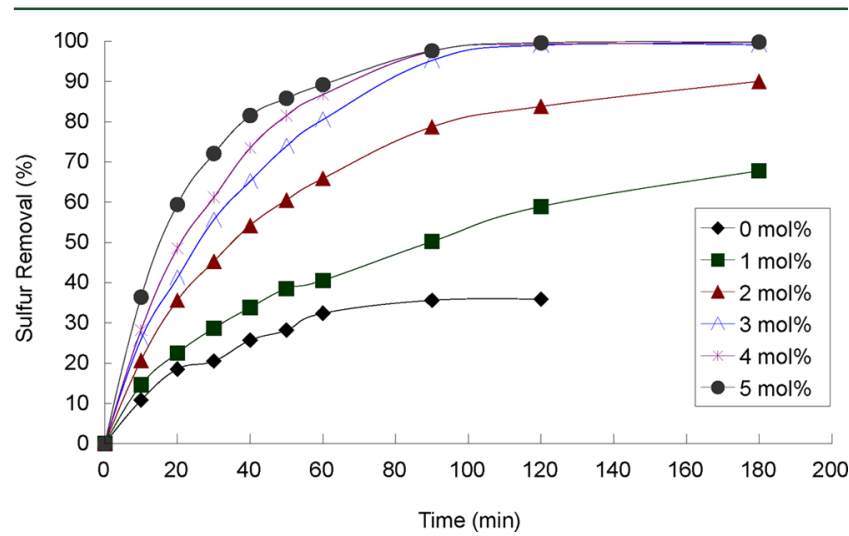

Figure 1. Sulfur removal for different amounts of MTO to model oil in the presence of $[\mathrm{BMIM}] \mathrm{BF}_{4}$. Experimental conditions: model oil, 10 $\mathrm{mL}$; IL, $2 \mathrm{~mL} ; n_{\mathrm{MTO}} / n_{\text {sulfur }}, 0-5: 100 ; n_{\mathrm{H}_{2} \mathrm{O}_{2}} / n_{\text {sulfur }}, 6$; and $T, 60{ }^{\circ} \mathrm{C}$.

only about $35 \%$ after $2 \mathrm{~h}$ when using mere $[\mathrm{BMIM}] \mathrm{BF}_{4}$ for desulfurization. However, it was increased up to about $68 \%$ after $3 \mathrm{~h}$ after adding $\mathrm{H}_{2} \mathrm{O}_{2}$ as the oxidant and $1 \mathrm{~mol} \%$ of MTO (relative to the sulfur concentration) as the catalyst to the system. While the MTO amount was increased up to $3 \mathrm{~mol} \%$, the sulfur removal could reach about $90 \%$ only after $1 \mathrm{~h}$. The extraction equilibrium was reached after $2 \mathrm{~h}$, and a maximum sulfur removal (99\%) was obtained. The data indicate that ECODS is efficient for removing the sulfur-containing compounds in the oil, even with a low catalyst loading. The desulfurization process could be further accelerated with MTO loading up to 4 or $5 \mathrm{~mol} \%$.

3.1.2. Influence of the IL Amount on the Sulfur Removal. The amount of IL was also found to be an important factor for the extraction process, which may significantly influence the final distribution of sulfur compounds in the oil and IL phases. It can be seen in Figure 2 that, when increasing the volume ratio between IL and model oil from $1: 10$ to $1: 1$, the sulfur removal was increased from 69.5 to $99 \%$ within $1.5 \mathrm{~h}$. The

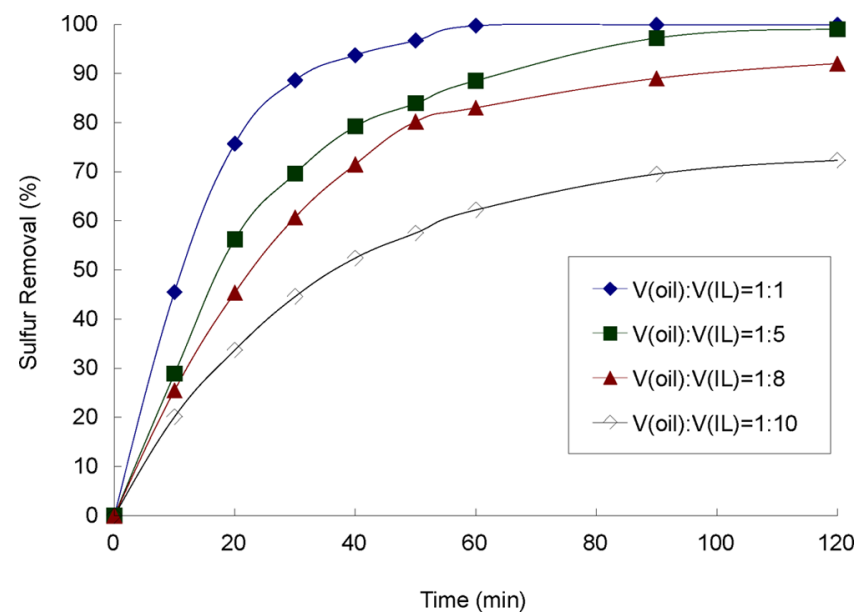

Figure 2. Sulfur removal for different volume ratios of $[\mathrm{BMIM}] \mathrm{BF}_{4}$ to model oil in the presence of $\mathrm{H}_{2} \mathrm{O}_{2}$. Experimental conditions: model oil, $1-10 \mathrm{~mL}$; IL, $1 \mathrm{~mL} ; n_{\mathrm{MTO}} / n_{\text {sulfur }}, 3: 100 ; n_{\mathrm{H}_{2} \mathrm{O}_{2}} / n_{\text {sulfur }}$, 6 ; and T, 60 ${ }^{\circ} \mathrm{C}$.

extraction equilibrium was reached within $1.5 \mathrm{~h}$ for all $\mathrm{IL}$ loading amounts, indicating that the conversion of thiophene in all cases was kept nearly unchanged, but the final sulfur removal was determined by the distribution of sulfur compounds in the oil and IL phases. The sulfur removal for both 1:1 and 1:5 ratios could reach almost $100 \%$ after $2 \mathrm{~h}$, but the final equilibrium of the 1:1 ratio was slightly faster than 1:5 because of the excess amount of applied IL.

3.1.3. Influence of the $\mathrm{H}_{2} \mathrm{O}_{2}$ Amount on the Sulfur Removal. Table 1 shows the effect of the $\mathrm{H}_{2} \mathrm{O}_{2}$ amount on

Table 1. Desulfurization of Model Oil with Different Amounts of $\mathrm{H}_{2} \mathrm{O}_{2}{ }^{a}$

\begin{tabular}{lccccc}
\multicolumn{1}{c}{ entry } & 1 & 2 & 3 & 4 & 5 \\
\hline$n_{\mathrm{H}_{2} \mathrm{O}_{2}} / n_{\text {sulfur }}$ & $2: 1$ & $4: 1$ & $6: 1$ & $8: 1$ & $10: 1$ \\
sulfur removal (\%) & 68 & 87 & 99 & 99 & 98
\end{tabular}

${ }^{a}$ Experimental conditions: model oil, $10 \mathrm{~mL} ; \mathrm{IL}, 2 \mathrm{~mL} ; n_{\mathrm{MTO}} / n_{\text {sulfur }}$, $3: 100 ; n_{\mathrm{H}_{2} \mathrm{O}_{2}} / n_{\text {sulfur }}, 2-10 ; t, 2 \mathrm{~h}$; and $\mathrm{T}, 60{ }^{\circ} \mathrm{C}$.

the sulfur removal in the presence of $[\mathrm{BMIM}] \mathrm{BF}_{4}$ at $60{ }^{\circ} \mathrm{C}$. According to the oxidation reaction of thiophene, at least 2 equiv of $\mathrm{H}_{2} \mathrm{O}_{2}$ is necessary theoretically to complete the reaction. However, only $68 \%$ of the sulfur removal was obtained when applying 2 equiv of $\mathrm{H}_{2} \mathrm{O}_{2}$, which means that a 2:1 ratio was not sufficient enough to oxidize thiophene. When increasing the molar ratio of $\mathrm{H}_{2} \mathrm{O}_{2}$ to substrate, the sulfur removal was increased significantly. The sulfur removal reached almost $100 \%$ for $6: 1$. This can be explained by the cycloaddition phenonmena of thiophene 1,1-dioxide formed after the oxidation reaction. As described above, the obtained oxidizing product thiophene 1,1-dioxide has the tendency to form its cycloaddition product. During the cycloaddition process, the intermidiate product 2 (as shown in Scheme 3 ) would be further oxidized by $\mathrm{H}_{2} \mathrm{O}_{2}$ in the system with a loss of the $\mathrm{SO}_{2}$ group on compound 2 . Accordingly, an excess amount of hydrogen peroxide is necessary to completely consume the substrate thiophene. ${ }^{30,31}$

3.1.4. Influence of the Temperature on the Sulfur Removal. Figure 3 shows the temperature effect on sulfur removal using $[\mathrm{BMIM}] \mathrm{BF}_{4}$ as an extractant. It had been found 


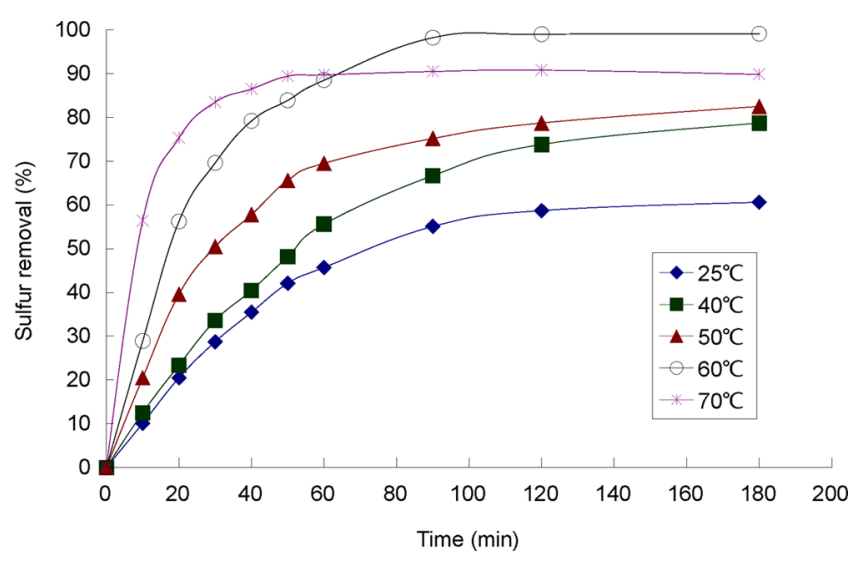

Figure 3. Sulfur removal at different temperatures. Experimental conditions: model oil, $10 \mathrm{~mL}$; IL, $2 \mathrm{~mL} ; n_{\mathrm{MTO}} / n_{\text {sulfur }}, 3: 100 ; n_{\mathrm{H}_{2} \mathrm{O}_{2}} /$ $n_{\text {sulfur }}, 6$; and $T, 60^{\circ} \mathrm{C}$.

by $\mathrm{Xu}$ et al. $^{15}$ that the sulfur removal was decreased when increasing the temperature from 30 to $50{ }^{\circ} \mathrm{C}$ in the case of the $\mathrm{V}_{2} \mathrm{O}_{5} / \mathrm{H}_{2} \mathrm{O}_{2}$-catalyzed ECODS process with the same IL. However, as the temperature was increased from 25 to $60{ }^{\circ} \mathrm{C}$ in our work, the sulfur removal was increased from 59 to $99 \%$ after $2 \mathrm{~h}$, indicating a good stability of $\mathrm{H}_{2} \mathrm{O}_{2}$ in the MTOcatalyzed ECODS system. A lower sulfur removal was observed when ECODS was conducted at $70{ }^{\circ} \mathrm{C}(91 \%)$ than that at 60 ${ }^{\circ} \mathrm{C}(99 \%)$, which may due to the higher decomposition rate of $\mathrm{H}_{2} \mathrm{O}_{2}$ at higher temperatures, leading to a lower oxidation degree of thiophene. Therefore, we conclude here that $60{ }^{\circ} \mathrm{C}$ is the optimal operating temperature for ECODS.
On the basis of all of the data achieved above, the preferable conditions for the MTO-catalyzed ECODS process would be $V_{\mathrm{IL}} / V_{\text {model oil }}=1: 5, n_{\mathrm{MTO}} / n_{\text {sulfur }}=3: 100, n_{\mathrm{H}_{2} \mathrm{O}_{2}} / n_{\text {sulfur }}=6, t=3 \mathrm{~h}$, and $T=60{ }^{\circ} \mathrm{C}$.

3.2. Proposed Mechanism of the ECODS System. Scheme 4 illustrates the catalytic cycles of the ECODS process catalyzed by MTO with IL as the solvent and extractant. $\mathrm{H}_{2} \mathrm{O}_{2}$ $(30 \%)$ and $[\mathrm{BMIM}] \mathrm{BF}_{4}$ were added to the model oil to obtain a biphasic solution. $\mathrm{H}_{2} \mathrm{O}_{2}$ was dissolved in IL and resulted in a colorless IL phase. The reaction started after adding MTO to the system, and the IL phase was changed to a yellow color, indicating the formation of monoperoxorhenium $\left[\mathrm{CH}_{3} \mathrm{ReO}_{2}\left(\mathrm{O}_{2}\right)\right]$ and bisperoxorhenium $\left[\mathrm{CH}_{3} \mathrm{ReO}\left(\mathrm{O}_{2}\right)_{2}\right]$ complexes. $^{23}$

Both the mono- and bisperoxorhenium complexes, proven by IR and ${ }^{1} \mathrm{H}$ NMR results, ${ }^{21}$ are regarded as active species toward sulfide oxidations. ${ }^{26}$ Thus, the oxidation process undergoes two cycles, namely, cycles A and B. At the beginning, thiophene is distributed in both oil and IL phases; thus, the oxidation reaction proceeds in both phases. However, because of the increased polarity of the oxidized products, they are extracted to the IL phase. Because an excess amount of $\mathrm{H}_{2} \mathrm{O}_{2}$ exists in the solution, the formed thiophene 1-oxide can be further oxidized to thiophene 1,1-dioxide. Thiophene 1,1-dioxide is then further converted to its cycloaddition products 3 and 4 (see Scheme 3 ), as confirmed by the ${ }^{1} \mathrm{H}$ NMR spectra (see section 3.1 ).

3.3. Oxidative Desulfurization of FCC Gasoline. Because the MTO/IL/ $\mathrm{H}_{2} \mathrm{O}_{2}$ system is highly effective for the desulfurization of model oil, the system was then applied to the Fushun FCC gasoline under the optimized conditions. Table 2

Scheme 4. Proposed Mechanism of Thiophene Oxidation

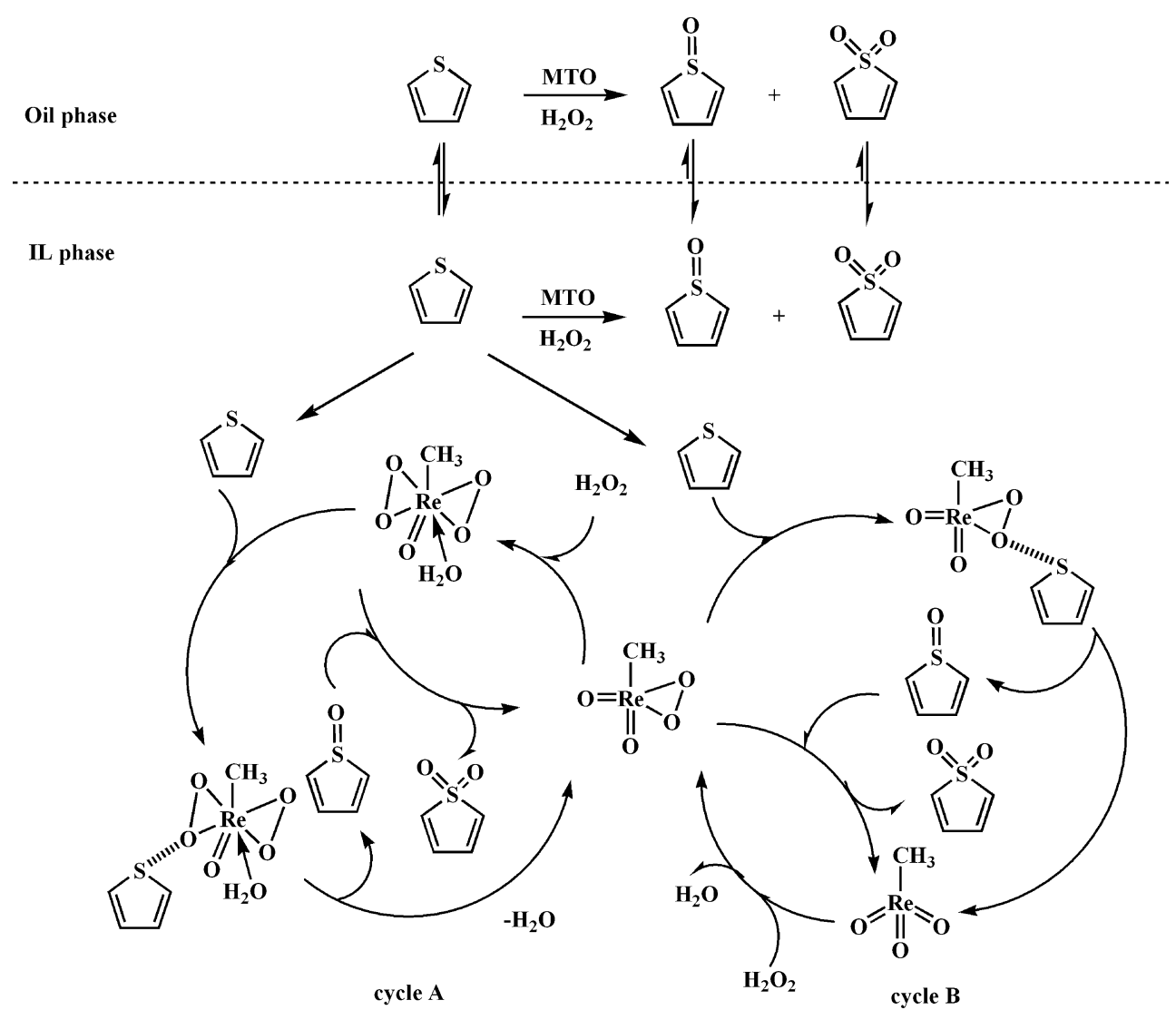


Table 2. Sulfur Compounds Present in the Fushun FCC Gasoline

\begin{tabular}{|c|c|c|c|}
\hline \multirow[b]{2}{*}{ group compounds } & \multirow[b]{2}{*}{ sulfur compounds } & \multicolumn{2}{|c|}{$\mathrm{S}$ concentration $(\mu \mathrm{g} / \mathrm{mL})$} \\
\hline & & $\begin{array}{l}\text { original } \\
\text { gasoline }\end{array}$ & $\begin{array}{c}\text { after } \\
\text { desulfurization }\end{array}$ \\
\hline mercaptan & $\mathrm{C}_{1}-\mathrm{C}_{6}$ mercaptan & 11.8 & \\
\hline thioether & $\mathrm{C}_{5}-\mathrm{C}_{8}$ thioether & 9 & \\
\hline thiophene & thiophene & 15.8 & 1.6 \\
\hline \multirow[t]{7}{*}{ alkyl thiophene } & 2-MTh & 3.8 & 2.0 \\
\hline & 3-MTh & 9.6 & 0.6 \\
\hline & $\mathrm{C}_{2}-\mathrm{Th}$ & 9.6 & 1.5 \\
\hline & 3-ETh & 1.8 & \\
\hline & DMTh & 2.2 & \\
\hline & $\mathrm{C}_{3}-\mathrm{Th}$ & 9.8 & 0.7 \\
\hline & $\mathrm{C}_{4}-\mathrm{Th}$ & 16.4 & 0.4 \\
\hline \multirow[t]{2}{*}{ thiophane } & thiophane & 4.8 & \\
\hline & 2-methyl thiophane & 6 & 1.1 \\
\hline \multirow[t]{2}{*}{ benzene thiophene } & BT & 5 & 2.6 \\
\hline & MBT & 3.4 & 1.8 \\
\hline \multirow[t]{2}{*}{ unknown sulfur } & unknown sulfur & 32.6 & 0.3 \\
\hline & total sulfur & 142 & 12.6 \\
\hline
\end{tabular}

demonstrates both the original sulfur and the remaining sulfur compound concentrations in the oil after desulfurization. The original sulfur concentration of Fushun FCC gasoline was about $142 \mu \mathrm{g} / \mathrm{mL}$ and remained only $12.6 \mu \mathrm{g} / \mathrm{mL}$ after desulfurization with sulfur removal of ca. $91 \%$. The dominant sulfur components in the oil are mercaptan, thioether, thiophene, and their derivatives, as well as less amounts of benzene thiophene (BT) or methyl-substituted benzene thiophene $(\mathrm{MBT})$. In the case of 2-methyl thiophene, BT or MBT, only $50 \%$ can be removed because of their steric constraints that make the active mono- or bisperoxorhenium species difficult to access sulfur atoms.

The hydrocarbon composition of the FCC gasoline was also determined to test the compositional change after desulfurization. It can be seen that the hydrocarbon composition showed almost no change after the ECODS process and the octane number value was reduced by only 0.7 (see Table 3 ), which was much lower than the reduction of the deep HDS process. ${ }^{32}$

3.4. Recycling of ILs. The ILs containing catalyst were recycled after the ECODS reaction. After each desulfurization

Table 3. Hydrocarbon Composition of Fushun FCC Gasoline

\begin{tabular}{llcc}
\multicolumn{1}{c}{ entry } & \multicolumn{1}{c}{ type of compound } & $\begin{array}{c}\text { original } \\
\text { gasoline }\end{array}$ & $\begin{array}{c}\text { after } \\
\text { desulfurization }\end{array}$ \\
1 & $\mathrm{C}_{4}$ total & 1.38 & 1.23 \\
2 & $\mathrm{C}_{5}$ total & 10.44 & 10.15 \\
3 & $\mathrm{C}_{6}$ total & 0.45 & 0.44 \\
4 & $\mathrm{C}_{7}$ total & 2.55 & 2.55 \\
5 & $\mathrm{C}_{8}$ total & 5.89 & 5.93 \\
6 & $\mathrm{C}_{9}$ total & 6.81 & 6.88 \\
7 & $\mathrm{C}_{10}$ total & 4.56 & 4.83 \\
8 & $\mathrm{C}_{11}$ total & 1.28 & 1.3 \\
9 & $\mathrm{C}_{12}$ total & 0.76 & 0.77 \\
group & alkenes & 29.61 & 29.24 \\
composition & aromatics & 21.54 & 21.93 \\
& alkanes + cycloparaffin & 48.26 & 48.27 \\
calculated RON & & 90.5 & 89.7 \\
calculated MON & & 81.4 & 80.7
\end{tabular}

run, the $\mathrm{IL}$ phase was decanted, washed with water at $0{ }^{\circ} \mathrm{C}$, and then evacuated in an oil bath at $80^{\circ} \mathrm{C}$ under vacuum for $10 \mathrm{~h}$ to remove water and most sulfides. Then, the recycled IL solution was applied for the next run, and no additional catalyst was added to the ECODS system. Despite the catalyst MTO being active toward the oxidation of sulfur compounds in the oil, it had been detected (by IR spectra) that part of MTO might decomposed into perrhenates. Actually, Herrmann et al. had reported that the active mono- and bisperoxorhenium complexes could decompose slowly into perrhente anion in the presence of $\mathrm{H}_{2} \mathrm{O}_{2}$ solution. ${ }^{20}$ For MTO, the symmetric and asymmetric vibrations of $\mathrm{Re}=\mathrm{O}$ were located at ca. 955 and $1000 \mathrm{~cm}^{-1}$. $^{29}$ However, two strong peaks at 839 and $899 \mathrm{~cm}^{-1}$, indicating the typical vibrations of $\mathrm{Re}=\mathrm{O}$ for perrhenates, were found in IR spectra for the recycled catalyst/IL system, indicating the decomposition of MTO in the system. Nevertheless, it was surprising to find that the system was still active toward the oxidation of sulfides. A detailed study on the catalytic behavior of perrhenate salts on the oxidation of sulfides and their effects toward desulfurization is currently under investigation in out laboratories and will be published elsewhere. The ILs had been recycled and reused 4 times, and the data showed only a slightly decrease of sulfur removal after each run, with the sulfur removal of $99,99,95$, and $96 \%$, respectively. The slight data decrease may due to some trace amount of oxidized sulfur compound contained in the IL after recycling, which lead to a slightly decrease of IL solubility. In general, the data indicated a good stability of the investigated IL ECODS system.

\section{CONCLUSION}

In conclusion, MTO has been used as a catalyst in the ECODS system for the first time. The results indicate that MTO is an effective catalyst for the oxidation of sulfur-containing compounds, such as thioethers and thiophenes, presented in the gasoline. In the study, the influence with respect to catalyst loading, IL and oil volume ratio, oxidant amount, and temperature on sulfur removal has been discussed. The suggested optimal ECODS conditions are $V_{\mathrm{IL}} / V_{\text {model oil }}=1: 5$, $n_{\mathrm{MTO}} / n_{\text {sulfur }}=3: 100, n_{\mathrm{H}_{2} \mathrm{O}_{2}} / n_{\text {sulfur }}=6, t=3 \mathrm{~h}$, and $T=60{ }^{\circ} \mathrm{C}$. Under such conditions, the sulfur removal for the model oil reached 99\% within $2 \mathrm{~h}$ and the sulfur concentration was reduced to about $12.6 \mu \mathrm{g} / \mathrm{mL}$ with a sulfur removal of $91 \%$ for the Fushun FCC gasoline (with the original sulfur concentration of $142 \mu \mathrm{g} / \mathrm{mL}$ ). The octane number of gasoline was reduced by only about 0.7 , and the group composition showed no significant changes after desulfurization. The examined ECODS system was proven to be a simple, mild, and environmentally friendly method for the deep desulfurization of gasoline.

\section{AUTHOR INFORMATION}

\section{Corresponding Authors}

*Telephone: +86-532-80662757. Fax: +86-0532-80662778. Email: lixb@qibebt.ac.cn.

*Telephone/Fax: +86-24-56863837. E-mail: slzang@lnpu.edu. cn.

\section{Notes}

The authors declare no competing financial interest. 


\section{ACKNOWLEDGMENTS}

Mingdong Zhou and Shuliang Zang thank the National Science and Technology Pillar Program (2012BAF03B02), the National Natural Science Foundation of China (21101085), and the Program for Liaoning Excellent Talents in University (LJQ2012031) for the financial support. Xuebing Li thanks the National Natural Science Foundation of China (U1162203) for financial support.

\section{REFERENCES}

(1) Esser, J.; Wasserscheid, P.; Jess, A. Green Chem. 2004, 6, 316322.

(2) Zhu, W. S.; Li, H. M.; Jiang, X.; Yan, Y. S.; Lu, J. D.; Xia, J. X. Energy Fuels 2007, 21, 2514-2516.

(3) Li, F. T.; Liu, R. H.; Wen, J. H.; Zhao, D. S; Sun, Z. M.; Liu, Y. Green Chem. 2009, 11, 883-888.

(4) Shafi, R.; Hutchings, G. J. Catal. Today 2000, 59, 423-442.

(5) Holbrey, J. D.; Lopez-Martin, I.; Rothenberg, G.; Seddon, K. R.; Silvero, G.; Zheng, X. Green Chem. 2008, 10, 87-92.

(6) Li, H. M.; He, L. N.; Lu, J. D.; Zhu, W. S.; Jiang, X.; Wang, Y.; Yan, Y. S. Energy Fuels 2009, 23, 1354-1357.

(7) Zhao, D. S.; Sun, Z. M.; Li, F. T.; Liu, R.; Shan, H. D. Energy Fuels 2008, 22, 3065-3069.

(8) Komintarachat, C.; Trakarnpruk, W. Ind. Eng. Chem. Res. 2006, 45, 1853-1856.

(9) Cheng, S. S.; Yen, T. F. Energy Fuels 2008, 22, 1400-1401.

(10) Schmidt, R. Energy Fuels 2008, 22, 1774-1778.

(11) Huang, C. P.; Chen, B. H.; Zhang, J.; Liu, Z. C.; Li, Y. X. Energy Fuels 2004, 18, 1862-1864.

(12) Chi, Y. S.; Li, C. P.; Jiao, Q. Z; Liu, Q. S.; Yan, P. F.; Liu, X. M.; Urs, W.-B. Green Chem. 2011, 13, 1224-1229.

(13) Wang, J. L.; Zhao, D. S.; Li, K. X. Energy Fuels 2010, 24, 25272529.

(14) Zhu, W. S.; Li, H. M.; Jiang, X.; Yan, Y. S.; Lu, J. D.; Xia, J. X. Energy Fuels 2007, 21, 2514-2516.

(15) Xu, D.; Zhu, W. S.; Li, H. M.; Zhang, J. T; Zou, F.; Shi, H.; Yan, Y. S. Energy Fuels 2009, 23, 5929-5933.

(16) Caero, L.; Cedeno, J. F.; Navarro, A.; Gutierrez-Alejandre, A. Catal. Today 2006, 116 (4), 562-568.

(17) Ramos-Luna, M. A.; Cedeño-Caero, L. Ind. Eng. Chem. Res. 2010, 50 (5), 2641-2649.

(18) Kong, L. Y.; Li, G.; Wang, X. S.; Wu, B. Energy Fuels 2006, 20, $896-902$.

(19) Zhao, D. S.; Li, K. X.; Wang, J. L. Energy Fuels 2009, 23, 38313834.

(20) Romão, C. C.; Kühn, F. E.; Herrmann, W. A. Chem. Rev. 1997, 97, 3197-3246.

(21) Zhu, Z.; Espenson, J. H. J. Am. Chem. Soc. 1996, 118, 99019907.

(22) Adam, W.; Balci, M.; Kilic, H. J. Org. Chem. 1998, 63, 85448546.

(23) Herrmann, W. A.; Fischer, R. W.; Scherer, W.; Rauch, M. U. Angew. Chem., Int. Ed. 1993, 32, 1157-1160.

(24) Owens, G. S.; Abu-Omar, M. M. Chem. Commun. 2000, 11651166.

(25) Betz, D.; Herrmann, W. A.; Kühn, F. E. J. Organomet. Chem. 2009, 694, 3320-3324.

(26) Owens, G. S.; Arias, J.; Abu-Omar, M. M. Catal. Today 2000, 55, 317-363.

(27) Brown, K. N.; Espenson, J. H. Inorg. Chem. 1996, 35, 72117216.

(28) Lo, W. H.; Yang, H. Y.; Wei, G. T. Green Chem. 2003, 5, 639642.

(29) Tosh, E.; Mitterpleininger, H. K. M.; Rost, A. M. J.; Veljanovski, D.; Herrmann, W. A.; Kühn, F. E. Green Chem. 2007, 9 (12), 12961298.

(30) Nagasawa, H.; Sugihara, Y.; Ishii, A.; Nakayama, J. Bull. Chem. Soc. Jpn. 1999, 72, 1919-1926.
(31) Nakayama, J.; Nagasawa, H.; Sugihara, Y.; Ishii, A. J. Am. Chem. Soc. 1997, 119, 9077-9078.

(32) Babich, I. V.; Moulijn, J. A. Fuel 2003, 82, 607-631. 